\title{
The physiological functions of iron regulatory proteins in iron homeostasis - an update
}

\section{De-Liang Zhang, Manik C. Ghosh and Tracey A. Rouault*}

Molecular Medicine Program, Eunice Kennedy Shriver National Institute of Child Health and Human Development, National Institute of Health, Bethesda, MD, USA

\section{Edited by:}

Raffaella Gozzelino, Instituto

Gulbenkian de Ciência, Portugal

\section{Reviewed by:}

Janis Lynne Abkowitz, University of

Washington, USA

Wolff Mayer Kirsch, Loma Linda

University Medical Center, USA

\section{*Correspondence:}

Tracey A. Rouault, Molecular Medicine Program, Eunice Kennedy Shriver National Institute of Child Health and Human Development, National Institute of Health, Bethesda, MD 20892, USA

e-mail: rouault@mail.nih.gov
Iron regulatory proteins (IRPs) regulate the expression of genes involved in iron metabolism by binding to RNA stem-loop structures known as iron responsive elements (IREs) in target mRNAs. IRP binding inhibits the translation of mRNAs that contain an IRE in the 5 'untranslated region of the transcripts, and increases the stability of mRNAs that contain IREs in the $3^{\prime}$ untranslated region of transcripts. By these mechanisms, IRPs increase cellular iron absorption and decrease storage and export of iron to maintain an optimal intracellular iron balance. There are two members of the mammalian IRP protein family, IRP1 and IRP2, and they have redundant functions as evidenced by the embryonic lethality of the mice that completely lack IRP expression (Irp1 $1^{-/-} / / r p 2^{-/-}$mice), which contrasts with the fact that $I r p 1^{-/-}$and $/ r p 2^{-/-}$mice are viable. In addition, Irp2 $2^{-/-}$mice also display neurodegenerative symptoms and microcytic hypochromic anemia, suggesting that IRP2 function predominates in the nervous system and erythropoietic homeostasis. Though the physiological significance of IRP1 had been unclear since Irp $1^{-/-}$animals were first assessed in the early 1990s, recent studies indicate that IRP1 plays an essential function in orchestrating the balance between erythropoiesis and bodily iron homeostasis. Additionally, Irp 1-/- mice develop pulmonary hypertension, and they experience sudden death when maintained on an iron-deficient diet, indicating that IRP1 has a critical role in the pulmonary and cardiovascular systems. This review summarizes recent progress that has been made in understanding the physiological roles of IRP1 and IRP2, and further discusses the implications for clinical research on patients with idiopathic polycythemia, pulmonary hypertension, and neurodegeneration.

Keywords: iron regulatory protein, iron responsive element, erythropoiesis, polycythemia, pulmonary hypertension, iron metabolism

\section{INTRODUCTION}

Iron is an indispensable element for all living organisms. Healthy adults contain $4-5 \mathrm{~g}$ of iron, about $65 \%$ of which is contained in hemoglobin where it participates in oxygen transport, 30-35\% is stored in liver, primarily in the storage protein, ferritin, and $1-2 \%$ is found in the form of iron-sulfur clusters or heme in the catalytic centers of numerous essential enzymes and multiprotein complexes such as the mitochondrial respiratory chain complexes, which contain twelve iron-sulfur clusters and seven hemes (Hentze et al., 2004; Darshan et al., 2010; Ganz and Nemeth, 2012b; Rouault, 2013). Due to the essential role of iron in vivo, iron deficiency can retard early development and impair cognitive ability of children, and iron deficiency anemia is a common nutrient deficiency disease worldwide. Conversely, because of the chemical reactivity of iron and its ability through Fenton chemistry to generate reactive hydroxyl radicals, which can then oxidize lipids, proteins and DNA, iron overload can damage cells and tissues, and lead to adverse consequences, such as those seen in hemochromatosis and hemolytic anemias. Therefore iron concentration has to be tightly regulated in the tissues and cells of organisms in vivo.

Mammals have developed sophisticated mechanisms to maintain appropriate iron concentrations in vivo. Thanks to the application of genetic screens and transgenic technology in biomedical research, our understanding of iron homeostasis regulation has advanced significantly in the last 15 years. Iron homeostasis in mammals is mainly regulated by a set of interlocking regulatory systems, including: (i) Hepcidinferroportin (FPN1) mediated regulation of serum iron levels, (ii) iron regulatory proteins (IRPs)/iron responsive element (IRE) mediated regulation of intracellular iron homeostasis, (iii) hypoxia inducible factor- $2 \alpha$ (HIF2 $\alpha$ ) mediated transcriptional regulation. These mechanisms regulate iron homeostasis at different levels, and the interaction and cooperation of these mechanisms fine-tunes iron levels in vivo. The IRP/IRE machinery post-transcriptionally regulates the expression of target genes according to cellular iron status, providing the fundamental regulation of iron homeostasis at the cellular level. Recently, studies in animal models have also shown that IRPs contribute significantly to systemic iron homeostasis and regulation of erythropoiesis. This review will begin with an overview of mammalian iron homeostasis, and will then focus on the more recent progress made in understanding the roles of IRP1 and IRP2 in cellular and systemic iron homeostasis. 


\section{OVERVIEW OF SYSTEMIC AND CELLULAR IRON METABOLISM}

For a healthy adult, about 25-30 mg of iron is needed daily for protein synthesis and cellular regeneration. To meet these requirements, about $90 \%$ of iron is acquired from the recycle of senescent red blood cells (RBC) by splenic macrophages, whereas the remaining $10 \%$ is absorbed from the diet to compensate for iron loss caused by bleeding, urinary excretion, and sloughing of epithelial and mucous cells (Rigby, 1971). More than $90 \%$ of daily iron consumption is used for RBC production in erythropoietic tissues, and the most prominent manifestation of iron deficiency is microcytic anemia (Rigby, 1971). The systemic iron homeostasis is mainly maintained by coordinating iron absorption through the duodenum, iron recycling through splenic macrophages, iron utilization in bone marrow by erythropoiesis, and iron storage in the liver. Because there is no known regulated iron excretion pathway, regulation of intestinal iron absorption plays an important role in maintenance of systemic iron homeostasis.

Mammals can absorb both heme iron and non-heme iron. Iron derived from heme, especially in the people of western societies, is estimated to contribute two thirds of the daily dietary iron absorption (West and Oates, 2008). However, the mechanism for heme absorption is not yet clear. In the last decade, several heme transporters have been identified, including heme carrier protein-1 (HCP1; Qiu et al., 2006; Laftah et al., 2009), HRG-1 (Rajagopal et al., 2008; White et al., 2013), and FLVCR1 and 2 (Quigley et al., 2004; Keel et al., 2008; Duffy et al., 2010), but their significance in intestinal iron absorption remains to be elucidated. For non-heme iron absorption, ferric iron [Fe(III)] in the diet must be reduced by a ferrireductase duodenal cytochrome b561 (Dcytb) to ferrous iron $[\mathrm{Fe}(\mathrm{II})]$ before the divalent metal transporter 1 (DMT1, also known as DCT1 or NRAMP2) can transport iron across the apical membrane into the cytosol of duodenal epithelial cells (socalled enterocytes; Gunshin et al., 1997; McKie et al., 2001). Once inside the cells, part of the newly absorbed iron is exported across the basolateral membrane by the iron export protein, ferroportin (FPN1, also known as MTP1 or IREG1) into circulating blood, where $\mathrm{Fe}(\mathrm{II})$ is converted to $\mathrm{Fe}$ (III) by a membrane-bound ferroxidase, hephaestin (HEPH), before binding to transferrin and circulating in blood to tissues and cells where iron is needed (Abboud and Haile, 2000; Donovan et al., 2000; McKie et al., 2000); enterocytes may use part of the iron absorbed for their own metabolic needs, whereas excess iron can be sequestered in ferritin for detoxification and storage, and sloughing of these cells at the end of their 3-4 days life span results in excretion of excess duodenal iron (Potten, 1998).

Because of the essential role of duodenal iron absorption in systemic iron homeostasis, duodenal uptake and transfer of iron is regulated by multiple mechanisms. HIF $2 \alpha$ has been shown to transcriptionally regulate the expression of iron transporters in iron deficiency and anemia conditions (Majmundar et al., 2010; Shah and Xie, 2013). There are hypoxia responsive elements (HREs) in the promoters of FPN1, DMT1, and DCYTB (also known as $C Y B R D 1)$ and the physiological importance of these HRE-HIF interactions has been demonstrated in the duodenum of Hif $2 \alpha$ conditional knockout mice, where expression of FPN1, DMT1, and DCYTB does not increase in response to iron deficiency, suggesting that HIF2 $\alpha$ has an important physiological role in transcriptional regulation of iron homeostasis (Mastrogiannaki et al., 2009; Shah et al., 2009). Secondly, hepcidin regulates the expression of FPN1 on the basolateral membrane of enterocytes and thereby adjusts iron export from enterocytes into blood (Ganz and Nemeth, 2011, 2012a). Hepcidin is a systemic iron regulatory hormone that is secreted mainly by the liver. Circulating hepcidin can bind FPN1 on the plasma membrane and induce its ubiquitination, internalization and degradation, and thereby reduce iron influx into blood in a feedback manner (Nemeth et al., 2004). Dysregulation of the hepcidin-FPN1 interaction causes the systemic iron overload disease, hemochromatosis, which highlights its significance in systemic iron homeostasis. Thirdly, the intracellular IRP/IRE machinery also regulates duodenal iron absorption, and IRP-related regulation will be discussed later in this review.

Unlike intestinal epithelial cells, other cells in vivo use holotransferrin (transferrin bearing two ferric iron) as the major iron source, and cells absorb iron through the transferrin (Tf)/transferrin receptor (TfR1) cycle. Holo-transferrin in the circulation binds to TfR 1 on plasma membranes to form TfR1/Tf/Fe complexes which then internalize to endosomes, whereupon acidification of endosomes induces the release of $\mathrm{Fe}$ (III) from Tf. Fe(III) undergoes reduction to $\mathrm{Fe}$ (II) by the endosomal ferrireductase STEAP3 before being transported by DMT1 across endosomal membranes into cytosol (Fleming etal., 1998; Ohgami etal., 2005). DMT1 may also directly transport non-transferrin-bound iron (NTBI) into cells in vivo, especially in conditions including hemochromatosis and hemolytic anemia when serum iron concentrations exceed the binding ability of transferrin, and therefore NTBI accumulates (Sarkar, 1970; Chua et al., 2004). Once inside the cytosol, part of the iron is taken up by mitochondria and used for heme and iron-sulfur cluster synthesis; excess iron can be exported out of the cells by the iron exporter FPN1, and much extra iron is sequestered in ferritin for detoxification and storage. Ferritin can store up to 4500 iron atoms in a spherical structure formed by 24 subunits of $\mathrm{H}$ - and L-ferritin, which self-organize in different ratios, depending on the tissue (Theil, 2012). The IRP/IRE machinery coordinates cellular iron absorption, export, utilization and storage, and thereby regulates intracellular iron homeostasis

\section{REGULATION OF INTRACELLULAR IRON HOMEOSTASIS BY THE IRP/IRE MACHINERY}

The IRP/IRE machinery registers intracellular iron levels, and coordinates iron absorption, export, utilization and storage, providing the fundamental machinery for regulation of intracellular iron metabolism (Rouault, 2006, 2013; Wallander et al., 2006; Muckenthaler et al., 2008). The IRE is a conserved stem-loop structure in the untranslated region (UTR) of target mRNAs. A typical loop has six nucleotides with the sequence of CAGUGN, in which the first $C$ and the fifth $G$ are believed to form a base-pair that stabilizes the structure (Sanchez et al., 2011). The six-nucleotide loop is connected to a stem that is separated into an upper and lower part by an unpaired bulge $\mathrm{C}$ residue that divides the stem in the middle. IRE sequences are highly 
conserved, and mutations of the IRE can cause iron dysregulation and diseases, suggesting a significant role of IRP/IRE regulation in iron homeostasis (Kato et al., 2001; Ismail et al., 2006). IREs are recognized and bound by IRP proteins, but the effect of IRP binding depends on the position of the IRE in the mRNA targets. If an IRE is located in the $5^{\prime} \mathrm{UTR}$ of target mRNAs, IRP binding can inhibit the translation of such target mRNAs, including L- and H-ferritin (iron storage protein) (Theil, 1990), FPN1 (iron export protein; Abboud and Haile, 2000; Donovan et al., 2000; McKie et al., 2000), erythroid 5-aminolevulinate synthase (eALAS or ALAS2, the first enzyme for heme synthesis; Dandekar et al., 1991), mitochondrial aconitase (ACO2, energy production; Kim etal., 1996; Schalinske etal., 1998), HIF2 $\alpha$ (erythropoiesis and hypoxia response; Sanchez et al., 2007), and Drosophila succinate dehydrogenase ( $\mathrm{SDH}$, citric acid cycle and mitochondrial electron transport chain; Kohler et al., 1995; Melefors, 1996). Conversely, if IREs are present in the $3^{\prime} \mathrm{UTR}$ of target mRNAs, IRP binding can increase their expression by stabilizing the mRNAs that include TfR1 and DMT1 (iron import proteins; Garrick etal., 2003). In summary, when activated by iron deficiency, IRPs bind the IREs of target mRNAs to increase iron absorption and decrease iron export, iron utilization and iron storage, thereby maintaining appropriate intracellular iron concentrations.

\section{IRON REGULATORY PROTEINS}

Iron regulatory proteins are soluble cytosolic proteins that alter their activities according to intracellular iron levels. There are two IRP proteins in mammalian cells, IRP1 and IRP2, which share $56 \%$ sequence identity. In addition, IRP2 has a cysteine-rich 73 amino acid insertion in its $\mathrm{N}$-terminal, but the function of the insertion is not clear yet (Pantopoulos, 2004). Both IRP1 and IRP2 are ubiquitously expressed, with IRP1 highly expressed in the kidneys, liver and brown fat, and IRP2 highly expressed in the central nervous system (Meyron-Holtz et al., 2004). IRP1 and IRP2 are regulated by different mechanisms. IRP1 is a bifunctional enzyme. In iron-replete conditions, IRP1 acquires a [4Fe-4S] cluster in its active cleft and displays cytosolic aconitase activity that catalyzes the conversion of citrate and isocitrate in the cytosol, which probably enhances NADPH generation and lipid synthesis (Tong and Rouault, 2007). In iron-deficient conditions, IRP1 loses its iron-sulfur cluster and acquires IRE-binding activity. The iron-sulfur cluster functions as the iron sensor of IRP1 that endows the protein with the ability to register intracellular iron concentration and adjust its activity accordingly (Rouault, 2006; Medenbach et al., 2011). In contrast to the bifunctional enzyme activity of IRP1, IRP2 does not have an iron-sulfur cluster and lacks aconitase activity, and its activity is regulated by ubiquitination and proteasomal degradation (Rouault, 2009; Salahudeen et al., 2009; Vashisht et al., 2009). Evidence from two independent groups demonstrated that IRP2 is targeted for proteasomal degradation by an E3 ubiquitin ligase complex that contains an F-box protein, FBXL5 (Salahudeen et al., 2009; Vashisht et al., 2009). FBXL5 has a hemerythrin domain that likely binds iron and oxygen, enabling it to function as a regulatory switch that determines the stability of FBXL5, and consequently regulates E3 ubiquitin ligase activity (Chollangi et al., 2012). In brief, iron deficiency and hypoxia destabilize FBXL5 protein, decrease the activity of the E3 ubiquitin ligase, and thereby increase IRP2 activity. Fbxl5 $5^{-/-}$mice were embryonic lethal, and the lethality could be rescued by deletion of $\operatorname{Irp} 2$, suggesting that the lethality is likely caused by augmented expression of IRP2 protein, a result that underscores the essential role of FBXL5-E3 ubiquitin ligase in regulation of IRP2 expression (Moroishi et al., 2011). IRP1 is also a target of the FBXL5-E3 ubiquitin ligase complex, and after it loses its $[4 \mathrm{Fe}-4 \mathrm{~S}]$ cluster by mutation of three cystine residues, IRP1 is down-regulated likely by the FBXL5-mediated proteasomal degradation pathway (Salahudeen et al., 2009; Vashisht et al., 2009). Because IRP1 is relatively stable in the cytosolic aconitase form at iron-replete conditions when FBXL5-E3 ubiquitin ligase is active, the physiological significance of the FBXL5-mediated proteasomal degradation pathway on IRP1 expression is still elusive (Recalcati et al., 2006).

\section{PHYSIOLOGICAL SIGNIFICANCE OF IRP1 AND IRP2}

The IRP/IRE machinery maintains intracellular iron homeostasis and plays a crucial role in development and normal physiology. Animals bred to lack both alleles of $\operatorname{Irp} 1$ and $\operatorname{Irp} 2$ are not viable, and further analyses have shown that embryos at the blastocyst stage display brown color and abnormal morphologies, supporting an essential role of IRPs in early development, before implantation of the embryo (Smith et al., 2006). In contrast, mice with either Irp1 or Irp2 deficiency are viable and fertile, suggesting that Irp proteins can compensate for the loss of one another and are functionally redundant (Meyron-Holtz et al., 2004). The essential role of Irp proteins is also highlighted by conditional knockout experiments which have shown that lack of Irp1 and Irp2 in the intestine of mice results in early death at around 4 weeks of age likely due to intestinal malabsorption and dehydration, and lack of Irp1 and Irp2 in hepatocytes causes liver failure and death of animals within 12 days postpartum (Galy etal., 2008, 2010). Conditional deletion of both Irp 1 and Irp2 in hepatocytes compromises iron-sulfur cluster and heme synthesis, and impairs mitochondrial functions, suggesting an essential role of Irps in supplying iron to mitochondria to maintain respiration. Though adult mice with ligand-induced deletion of both Irp 1 and Irp2 in duodenal enterocytes responded well to iron loading and erythropoietic stimulation, these mice displayed reduced iron absorption and iron accumulation in duodenal enterocytes, suggesting that Irps play an important role in adjusting duodenal iron absorption by regulating ferritin expression to create a ferritin dependent "mucosal block" (Galy et al., 2013).

\section{PHYSIOLOGICAL SIGNIFICANCE OF IRP2}

Though deletion of both Irp1 and Irp2 is embryonic lethal, mice with deletion of either Irp1 or Irp2 are viable and fertile (MeyronHoltz et al., 2004). Irp2 deficiency causes iron misregulation in the duodenum, central nervous system, and most prominently in motor neurons of spinal cord; misregulation is characterized by increased expression of ferritin, decreased expression of TfR1, and significant iron accumulation in the duodenal mucosa and neurons throughout the brain (LaVaute et al., 2001). Iron misregulation correlates with axonal degeneration and neuronal death in 
the brain and spinal cord, and animals in late stages of adulthood display a movement disorder characterized by abnormal gait, tremor, and hind-limb paralysis (LaVaute et al., 2001; Jeong et al., 2011). Compared with $\operatorname{Irp} 2^{-/-}$mice, loss of one more copy of $\operatorname{Irp} 1$ in $\operatorname{Irp} 1^{+/-} \operatorname{Irp} 2^{-/-}$mice exacerbates the neurodegenerative symptoms as evidenced by the increased myelin dense bodies in the ventral spinal cord in the region where motor neurons are found (a hallmark of neurodegeneration), increased stress markers, increased macrophage infiltration, and decreased diameters of motor neuronal axon bundles, suggesting that there is a dosage effect of Irp1 and Irp2 deficiency and confirming that neurodegenerative symptoms of $\operatorname{Irp} 2^{-/-}$mice are caused by iron dysregulation. Deficiency of Irp 2 increases the expression of the iron storage protein ferritin and decreases expression of the iron importer TfR1, leading to functional iron deficiency (lack of biologically available iron) in conjunction with apparent ferric iron overload caused by sequestration of iron in ferritin; and the notion that there is functional iron deficiency is also supported by deficiency of mitochondrial complex I/II activity (Figure 1; Jeong et al., 2011). The neurodegenerative symptoms of Irp2 $2^{-/-}$ mice were improved by activation of IRP1 activity with oral treatment by Tempol (4-hydroxy-2,2,6,6-tetramethylpiperidin-1oxyl), a scavenger of reactive oxygen species, which was shown to destabilize the iron-sulfur cluster ligand of IRP1 and restore its IRE-binding activity (Ghosh et al., 2008; Wilcox and Pearlman, 2008). The neurodegenerative symptoms of $\operatorname{Irp} 2^{-/-}$mice were also improved by deletion of one allele of ferritin- $\mathrm{H}$ chain, which limited iron sequestration and increased intracellular iron availability. These studies support that lack of IRE-binding activity of IRP2 and subsequent derepression of ferritin translation cause the neurodegenerative diseases of Irps deficient animals (Ghosh et al., 2008; Jeong et al., 2011). The neurodegenerative symptoms of $\operatorname{Irp} 2^{-/-}$mice were also assessed by other two groups in independent $\operatorname{Irp} 2^{-/-}$mouse colonies. Compared with the neurodegenerative symptoms characterized by ataxia, tremor and motor impairment associated with iron deposit in the white matter and nuclei throughout the brain in the $\operatorname{Irp} 2^{-/-}$mice of our group (LaVaute etal., 2001; Jeong etal., 2011), one group found that while their $\operatorname{Irp} 2^{-/-}$mice displayed discrete impairment of balance and/or motor coordination, they did not find iron deposit with Perl's-DAB iron staining and did not find evidence of neuronal degeneration in the brain (Galy et al., 2006); the other group found that their $\operatorname{Irp} 2^{-/-}$mice had significant locomotor dysfunction and increased iron deposits in the cortex, mid-brain and cerebellum of $\operatorname{Irp} 2^{-/-}$mice, but they did not find cellular degeneration with Fluoro-Jade staining (Zumbrennen et al., 2009). The locomotor dysfunction displayed by these three $\operatorname{Irp} 2^{-/-}$mouse colonies confirms the significant role of Irp2 in mouse neuronal system and also suggests that the discrepancy is likely from either different mouse genetic backgrounds or differences in experimental assessement, but not due to off-target effects as was suggested before (Galy et al., 2006). Since IRP1 and IRP2 have redundant functions, deletion of one copy of $\operatorname{Irp} 1$ in $\operatorname{Irp} 2^{-/-}$mice probably could exacerbate the neurodegenerative symptoms and provide more information of IRPs function in the other two $\operatorname{Irp} 2^{-/-}$mouse colonies. Further, conditional knockout of both $\operatorname{Irp} 1$ and $\operatorname{Irp} 2$ in neurons as in hepatocytes and enterocytes could shed light on the role of
IRPs in neuronal system, although complete loss of Irps has been lethal in several settings (Smith et al., 2006; Galy et al., 2008, 2010, 2013).

Irp $2^{-/-}$mice also display microcytic hypochromic anemia (Cooperman etal., 2005; Galy etal., 2005). Erythroblasts of Irp $2^{-/-}$mice have decreased TfR1 expression and iron levels, and increased protoporphyrin IX levels, supporting an iron-limited erythropoiesis model. Irp2 deficiency destabilizes TfR1 mRNA, and lack of TfR1 protein causes iron deficiency and eventually leads to microcytic anemia. The microcytic anemia of $\operatorname{Irp} 2^{-/-}$ mice suggests that Irp2 plays a dominant role in regulating iron homeostasis in erythroid cells (Figure 1). While the neurodegenerative symptoms of $\operatorname{Irp} 2^{-/-}$are corrected by Tempol treatment, the treatment did not improve the microcytic anemia (Ghosh et al., 2008). Analogously, while Tempol treatment significantly converted Irp1 fraction from cytosolic aconitase form to IRE-binding form in forebrain lysate, which likely compensated the loss of IREbinding activity in the brain of $\operatorname{Irp} 2^{-/-}$mice, Tempol treatment did not increase the IRE-binding activity of Irp 1 in erythroblasts, likely because Irp1 is already mainly in the IRE-binding form in erythroblasts (Ghosh et al., 2008).

In addition to the microcytic anemia and neurodegenerative symptoms, Irp $2^{-/-}$mice displayed iron overload in duodenum and liver, but interestingly, these animals also displayed iron deficiency in the spleen and bone marrow (Cooperman et al., 2005; Galy et al., 2005). Conditional deletion of Irp2 in mouse duodenal enterocytes and liver hepatocytes repeats the iron overload phenotype of duodenum and liver, suggesting that iron overload in these two tissues is likely due to cell-autonomous functions of Irp2 deficiency in enterocytes and hepatocytes (Ferring-Appel et al., 2009). In contrast, conditional deletion of Irp2 in mouse splenic macrophages did not produce the splenic iron deficiency seen in $\operatorname{Irp} 2^{-/-}$mice, suggesting that the splenic iron deficiency of $\operatorname{Irp} 2^{-/-}$mice is likely secondary to iron misregulation in other cell types. Considering that (i) both spleen and bone marrow macrophages of $\operatorname{Irp} 2^{-/-}$mice display iron deficiency, (ii) both spleen and bone marrow are erythropoietic tissues, (iii) splenic macrophages play an essential role in recycling iron from senescent RBC, the iron deficiency of splenic macrophages probably results from reduced acquisition of iron from red cell turnover in anemic $\operatorname{Irp} 2^{-/-}$mice. Conditional deletion of Irp2 in erythroblasts might shed light on the pathogenesis of splenic iron deficiency.

\section{PHYSIOLOGICAL SIGNIFICANCE OF IRP1}

Though both IRP1 and IRP2 are ubiquitously expressed and show similar binding affinities for target IREs in in vitro experiments, $\operatorname{Irp} 1^{-1-}$ and $\operatorname{Irp} 2^{-/-}$mice display different phenotypes (Henderson et al., 1993; Kim et al., 1995). Because the protein levels and IRE binding activities of IRP1 in electrophoresis mobility shift assays are much higher than those of IRP2 in cultured cells and in certain tissues such as liver and kidneys, the physiological significance of IRP1 has been relatively elusive. In contrast to the neurodegeneration and anemia symptoms of $\operatorname{Irp} 2^{-/-}$mice, $\operatorname{Irp1} 1^{-/-}$mice initially appeared asymptomatic and the physiological significance of IRP1 in iron metabolism was unclear. However, evidence from $\operatorname{Irp} 1^{-/-}$mice has recently emerged, which indicates that IRP1 


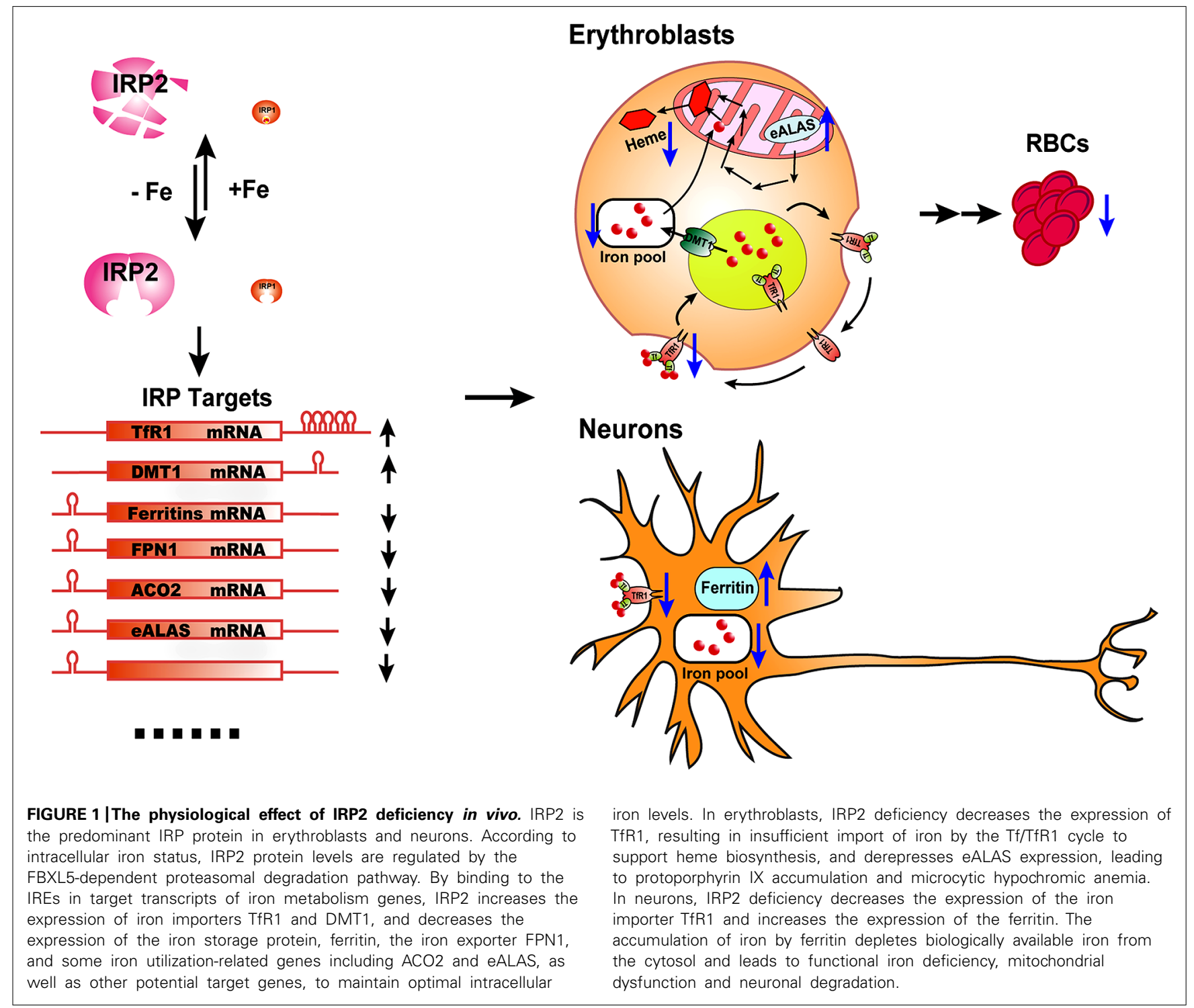

plays an essential role in regulation of systemic iron homeostasis and erythropoiesis.

\section{PHYSIOLOGICAL SIGNIFICANCE OF IRP1 IN ERYTHROPOIESIS AND SYSTEMIC IRON HOMEOSTASIS}

In contrast to $\operatorname{Irp} 2^{-/-}$mice that develop microcytic hypochromic anemia with hematocrits of about $36 \%$, adult $\operatorname{Irp} 1^{-/-}$mice produce more RBCs than wild type animals (hematocrit $\sim 50$ vs. $\sim 45 \%$, Irp $1^{-/-}$vs. wild type; Cooperman et al., 2005; Ghosh et al., 2013). High hematocrits were also observed in 4-6 weeks old mice of a different colony where two research groups found that $\operatorname{Irp} 1^{-/-}$ mice had hematocrits of more than 70\% (Pawlus and Hu, 2013; Wilkinson and Pantopoulos, 2013). However, these researchers

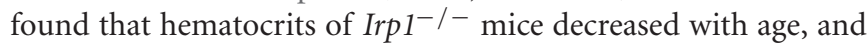

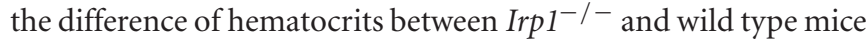
disappeared after 8 weeks of age. We also checked the hematocrits of Irp1 $1^{-/-}$mice in different ages (from 4 weeks to 14 months old), but did not find a significant decrease of the hematocrits of

mice older than 8 weeks of age (Zhang et al., unpublished data), and the reason for the inconsistent observations is not yet clear. More striking results are obtained from $\operatorname{Irp}^{-/-}$mice that are maintained on an iron-deficient diet (Ghosh et al., 2013). In contrast to the general observation that iron deficiency causes iron deficiency anemia, maintenance on an iron-deficient diet significantly increased the hematocrits of $\operatorname{Irp1^{-/-}}$ mice from about $50 \%$ to more than $60 \%$. Serum erythropoietin (EPO) levels of $\operatorname{Irp} 1^{-/-}$mice were more than seven-fold higher than that in wild type mice maintained on an iron-deficient diet, and animals with these high EPO levels developed splenomegaly and increased splenic erythropoiesis, supporting a model that there is EPO-dependent extracellular erythropoiesis in $\operatorname{Irp}^{-/-}$mice. HIF2 $\alpha$ is the master transcription factor in vivo that regulates EPO levels and subsequent RBC production according to both hypoxia and iron status (Semenza, 2009; Haase, 2013). HIF2 $\alpha$ mRNA has an IRE in its $5^{\prime}$ UTR with an initially unknown significance (Sanchez et al., 2007). In the renal carcinoma cell line, 
786-O cells, HIF2 $\alpha$ expression is increased by Irp1 knockdown but not Irp2 knockdown, suggesting that Irp1 probably plays a major function in repressing HIF $2 \alpha$ translation by binding to its $5^{\prime}$ IRE in these particular cells (Zimmer et al., 2008). Irp1 but not Irp2 deficiency significantly increased the percentage of HIF $2 \alpha$ mRNA found in the polysomal fractions of mouse kidneys and liver, proving that Irp 1 but not Irp 2 represses HIF $2 \alpha$ mRNA translation in cells of these two tissues in vivo (Anderson et al., 2013; Wilkinson and Pantopoulos, 2013). Thus, in $\operatorname{Irp1} 1^{-/-}$mice, Irp1 deficiency derepresses HIF $2 \alpha$ translation, which transcriptionally increases EPO expression and subsequently drives red blood production, leading to polycythemia as a consequence (Anderson et al., 2013; Ghosh et al., 2013; Wilkinson and Pantopoulos, 2013). Notably, $\operatorname{Irp1} 1^{-/-}$mice have severe iron deficiency as evidenced by low serum iron levels and reduced stainable tissue iron compared with wild type animals, which is likely caused by increased erythropoiesis that channels iron into the production of red cells, and consequently depletes Tf bound iron in blood and tissue iron stores.

The polycythemia of $\operatorname{Irp1^{-/-}}$ mice and its exacerbation by iron deficiency suggest a crucial role of Irp1 in regulating systemic iron levels and erythropoiesis (Figure 2). HIF2 $\alpha$ is regulated at the posttranslational level by prolyl hydroxylases (PHDs) that use oxygen and iron as substrates to hydroxylate HIF $2 \alpha$ at two conserved proline residues. Following hydroxylation, HIF2 $\alpha$ undergoes ubiquitination by the von Hippel-Lindau E3 ubiquitin ligase and is subsequently degraded through the proteasomal pathway (Majmundar et al., 2010; Lee and Percy, 2011; Yoon et al., 2011; Haase, 2013). Hence, HIF $2 \alpha$ can sense hypoxia and iron deficiency, and then increases EPO expression and drives red blood production, a process that consumes large amounts of iron. The regulation of HIF $2 \alpha$ translation by Irp 1 provides a safeguard that prevents

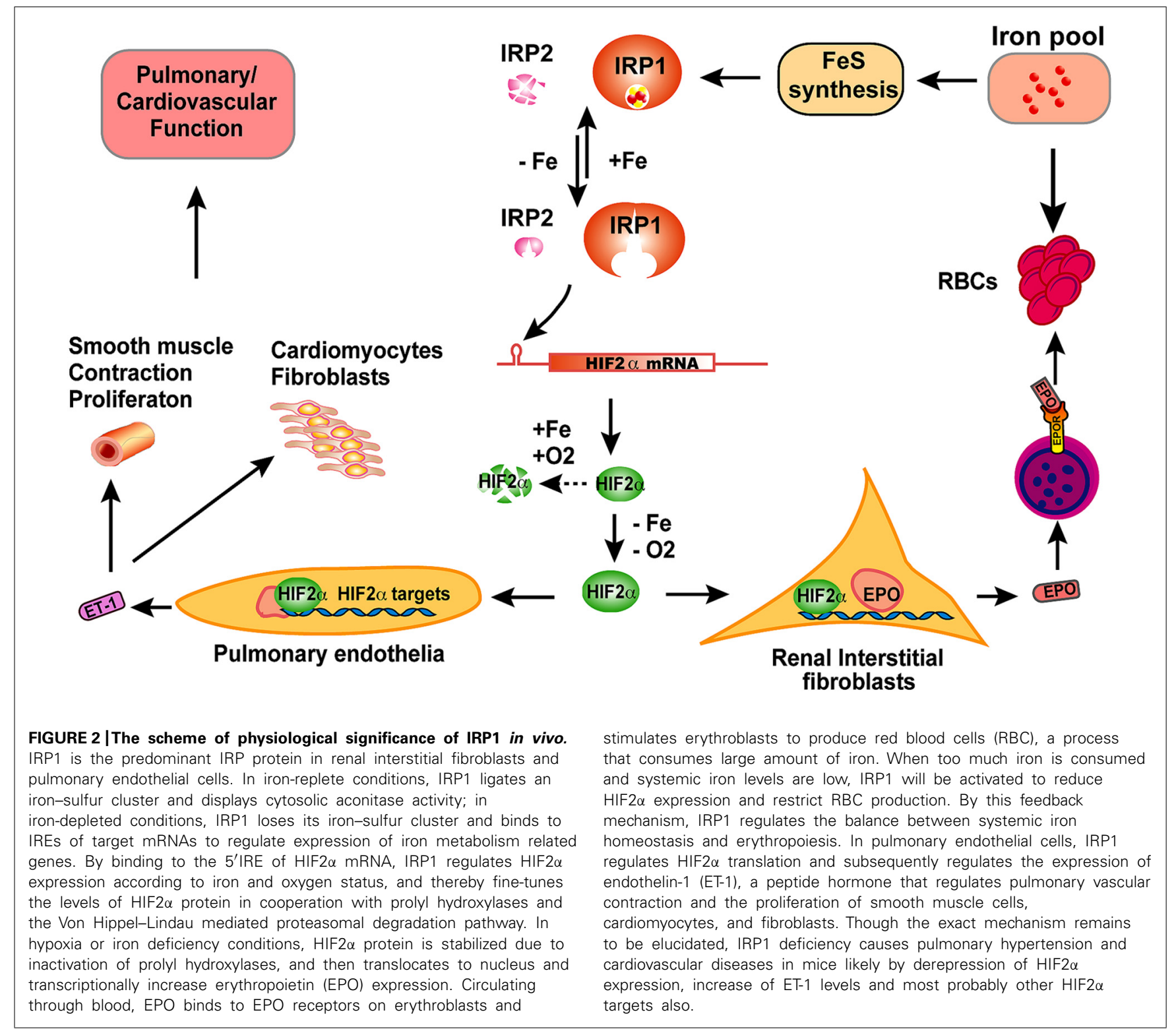


erythropoiesis from consuming too much iron to deplete systemic iron. While HIF $2 \alpha$ senses hypoxia and stimulates EPO expression and RBC production, Irp1 fine-tunes HIF2 $\alpha$ expression to ensure that there is enough iron available for iron-sulfur cluster synthesis; if intracellular iron levels are low, iron-sulfur cluster synthesis is impaired and IRP1 will be converted to the IRE-binding form, which represses HIF $2 \alpha$ translation, and thereby decreases RBC production to restore systemic iron balance (Figure 2). $\operatorname{Irp1} 1^{-/-}$ mice on an iron-deficient diet have increased polycythemia, severe iron deficiency, and sudden death due to peritoneal hemorrhage, which emphasizes the crucial role of Irp1 in systemic iron homeostasis and erythropoiesis (Ghosh et al., 2013). Maintenance of Irp $1^{-1-}$ animals in $10 \%$ oxygen for 3 weeks can increase the hematocrits of $\operatorname{Irp1} 1^{-/-}$mice to as high as $80 \%$, compared to $65 \%$ in wild type mice, highlighting the significance of IRP1 in systemic iron homeostasis and erythropoiesis under hypoxia (Zhang et al., unpublished data). Mice that inducibly express a constitutively active IRP1 mutant (IRP1*) develop macrocytic anemia, probably due to impaired erythropoiesis as displayed by increased erythroid progenitor and decreased numbers of mature cells (Casarrubea et al., 2013). Erythroblasts of IRP1* mice have higher TfR1 expression compared to wild type animals, which could potentially cause iron overload and impair normal erythropoiesis. In addition, high levels of Irp 1 are expected to repress HIF $2 \alpha$ translation and subsequently reduce EPO levels and RBC production. The macrocytic anemia of IRP1* highlights the importance of IRP/IRE balance in iron and erythropoiesis homeostasis.

In addition to its function in the regulation of erythropoiesis and systemic iron homeostasis, IRP1 probably also plays a role in coordinating intracellular Fe-S cluster and heme synthesis in erythroid cells (Wingert et al., 2005; Ye and Rouault, 2010; Chung et al., 2014). Because IRP1 has a [4Fe-4S] cluster as the sensor to adjust its IRE-binding activity, IRP1 can sense Fe-S cluster deficiency and potentially repress the translation of ALAS2 (eALAS) by binding to a IRE in its $5^{\prime}$ UTR. As ALAS2 is the first enzyme of the heme synthesis pathway, translational repression by IRP proteins can coordinate the synthesis of Fe-S clusters and heme (Dandekar et al., 1991; Wingert et al., 2005; Chung et al., 2014). Deficiency of glutaredoxin 5 (GLRX5), a scaffold protein required for mitochondrial Fe-S cluster synthesis, activated IRP1, which inhibited ALAS2 translation and subsequently led to anemia in zebrafish, suggesting a role of IRP1 in coordinating Fe-S cluster and heme synthesis (Wingert et al., 2005). Consistent with the zebrafish studies, RNAi knockdown of GLRX5 in K562 cells markedly reduced ALAS2 expression, and deficiency of GLRX5 in a patient caused by an intronic mutation that caused missplicing significantly increased the IRE-binding activity of IRP1, and caused sideroblastic anemia (Camaschella etal., 2007; Ye etal., 2010). IRP1 deficiency significantly increased protoporphyrin levels in erythroid cells with heterozygous deficiency of mitoferrin 1, the major mitochondrial iron importer in erythroid cells, also suggesting that IRP1 is an important link between Fe-S cluster and heme synthesis (Shaw et al., 2006; Chung et al., 2014). The evidence suggests that IRP1 likely plays an important role in orchestrating the heme and Fe$S$ cluster synthesis in erythroid precursors; however, the role of IRP2 was not really tested, considering that: (1) Zebrafish do not have an IRP2 homolog (Wingert et al., 2005); (2) The effect of
IRP2 deficiency on protoporphyrin levels in erythroid precursors with heterozygous mitoferrin 1 deficiency was not checked (Chung et al., 2014); (3) IRP2 expression was also significantly increased in GLRX5 deficient fibroblasts (Ye et al., 2010); (4) Irp2 $2^{-/-}$mice, but not $\operatorname{Irp1} 1^{-/-}$mice, have increased protoporphyrin IX levels (Cooperman et al., 2005). Thus, the roles of IRP1 and IRP2 in coordinating heme and Fe-S cluster synthesis in erythroid precursors may require further investigation.

\section{PHYSIOLOGICAL SIGNIFICANCE OF IRP1 IN PULMONARY AND CARDIOVASCULAR SYSTEM}

In addition to the essential role of IRP1 in maintaining erythropoiesis and systemic iron homeostasis, IRP1 also plays an important role in pulmonary and cardiovascular system (Figure 2). $\operatorname{Irp1} 1^{-/-}$mice displayed cardiac hypertrophy and pulmonary hypertension, two severe human diseases with unclear pathogenesis (Ghosh et al., 2013). HIF2 $\alpha$ has been previously implicated in the pathogenesis of pulmonary hypertension. Heterozygous deficiency of HIF $2 \alpha$ protects mice against developing pulmonary hypertension and right ventricular dysfunction during prolonged hypoxia, suggesting that HIF $2 \alpha$ is involved in pathogenesis of pulmonary hypertension (Brusselmans et al., 2003). Chuvash polycythemia is a hereditary disease caused by VHL ${ }^{\mathrm{R} 200 \mathrm{~W}}$ mutation that disrupts the degradation pathway of HIF $\alpha$ and consequently increases HIF $2 \alpha$ protein to high levels (Hickey et al., 2007). Chuvash polycythemia patients and a corresponding mouse model with a VHL ${ }^{\mathrm{R} 200 \mathrm{~W}}$ mutation develop polycythemia and pulmonary hypertension, and the pulmonary hypertension of the mouse model is improved by deletion of one allele of Hif $2 \alpha$, suggesting that there is a pathogenic role of HIF $2 \alpha$ in this disease (Bushuev etal., 2006; Hickey et al., 2010; Formenti et al., 2011). Endothelin-1, a potent vasoconstrictor and HIF target, is significantly increased in Chuvash mice and could be a downstream effector molecule in the pathogenesis of pulmonary hypertension (Bushuev et al., 2006; Hickey et al., 2010; Thorin and Clozel, 2010; Shao et al., 2011). HIF2 $\alpha$ expression is significantly increased in cultured primary endothelial cells of $\operatorname{Irp} 1^{-/-}$mice, and endothelin-1 expression is also significantly increased in lung tissues of $\operatorname{Irp} 1^{-/-}$mice, supporting a pathogenic role of these molecules in the pulmonary hypertension (Ghosh et al., 2013). However, preliminary results of $\operatorname{Irp1} 1^{-/-}$mice did not reveal significant pulmonary vascular remodeling, in contrast to the Chuvash and the prolonged-hypoxia mouse models, and thus the mechanism underlying the pulmonary hypertension of $\operatorname{Irp} 1^{-/-}$mice is not very clear yet. Low iron treatment significantly increases EPO expression and exacerbates the polycythemia of $\operatorname{Irp} 1^{-/-}$ mice, which could be attributed to the stabilization of HIF $2 \alpha$ by iron deficiency; in contrast, the iron-deficient diet did not exacerbate the pulmonary hypertension of $\operatorname{Irp} 1^{-/-}$mice, and the endothelin-1 levels were not altered either, suggesting that there are mechanistic differences in the pathophysiology of polycythemia and pulmonary hypertension. Analysis of the underlying molecular pathophysiology could shed light on the pathogenesis of these diseases. The IRP1/HIF $2 \alpha$ interaction in kidneys represents a mechanism that protects systemic iron homeostasis during erythropoiesis by preventing red cells production from depleting systemic iron, whereas the evolutionary rationale for the 
IRP1/HIF $2 \alpha$ interaction in pulmonary vascular function is not yet clear (Figure 2).

Maintenance on an iron-deficient diet also significantly decreases life span of $\operatorname{Irp} 1^{-/-}$mice. From the age of 3 months old, $\operatorname{Irp1} 1^{-/-}$mice on the iron-deficient diet are prone to sudden death in which apparently healthy mice die without warning (Ghosh et al., 2013). Pathological analyses of mouse carcasses revealed that these mice died of abdominal hemorrhage around the perinephric area, suggesting that there is an essential role of IRP1 in the vascular system. Considering that the iron-deficient diet exacerbates the polycythemia of Irp1 $1^{-/-}$mice by stimulating HIF $2 \alpha$ expression, HIF $2 \alpha$ probably also plays a role in the peritoneal hemorrhage. Notably, Chuvash polycythemia patients, who have high HIF2 $\alpha$ expression, also have increased incidence of thrombotic events, major bleeding episodes, and premature mortality, suggesting that there are probably similar mechanisms operating in Chuvash polycythemia patients and the $\operatorname{Irp}^{-/-}$mouse models (Gordeuk and Prchal, 2006). Coagulation factor VIII (FVIII) is an essential blood-clotting protein, and high levels of FVIII are reported to associate with increased risk of deep vein thrombosis and pulmonary embolism (Jenkins et al., 2012). An alternative transcript variant 2 of FVIII has a potential 5'IRE that, if functional, could derepress FVIII expression in IRP1 deficient animals or patients (Livesey etal., 2012). The expression and role of FVIII in the phenotypes associated with the $\operatorname{Irp} 1^{-/-}$mouse model warrant investigation.

\section{DIFFERENT PHENOTYPES OF Irp1-/- AND Irp2-/- MICE ARE LIKELY CAUSED BY CELL-SPECIFIC EXPRESSION}

The relative functions of IRP1 and IRP2 have been a subject of debate since they were identified two decades ago. On one hand, IRP1 and IRP2 are highly conserved in sequence and displayed similar binding affinity to their target in in vitro experiments (Henderson etal., 1993; Kim etal., 1995); on the other hand, IRP1 and IRP2 have different regulatory mechanisms with IRP1 functioning as a bifunctional protein and IRP2 being degraded through the proteasomal pathway. The polycythemia and pulmonary hypertension phenotype of $\operatorname{Irp} 1^{-/-}$mice and the anemia and neurodegeneration phenotype of $\operatorname{Irp} 2^{-/-}$mice likely support a unique functions of IRP1 and IRP2 in erythropoiesis/cardiovascular regulation and erythroblasts/nervous system, respectively. However, a recent study, which analyzed the endogenous transcripts bound in vitro by overexpressed IRP1 and IRP2 proteins with microarray, showed that IRP1 and IRP2 shared 44 transcripts including the transcripts that had been confirmed in literature, i.e., FTL, FTH, TfR1, DMT1, FPN1, ACO2, eALAS, and HIF2 $\alpha$ (Sanchez et al., 2011). Derepression of the shared target HIF $2 \alpha$ most likely causes the polycythemia and pulmonary hypertension of $\operatorname{Irp1}^{-/-}$mice (Anderson et al., 2013; Ghosh et al., 2013; Wilkinson and Pantopoulos, 2013), and dysregulation of the shared targets ferritin, TfR1, and eALAS likely lead to the diseases of Irp2 $2^{-/-}$mice (LaVaute et al., 2001; Cooperman et al., 2005; Galy et al., 2005; Ferring-Appel et al., 2009; Jeong et al., 2011; Ghosh et al., 2013). IRP1 expression is very high relative to IRP2 in the kidneys and lung, whereas IRP2 expression is very high in the brain, which is consistent with the symptoms of $\operatorname{Irp1} 1^{-/-}$and $\operatorname{Irp} 2^{-/-}$mice in affected tissues, suggesting that the differences in the phenotypes of $\operatorname{Irp} 1^{-/-}$and $\operatorname{Irp} 2^{-/-}$mice are most likely caused by differences in the cell-specific expression of these two proteins (Figures 1 and 2; Meyron-Holtz et al., 2004; Ghosh et al., 2008, 2013). Nevertheless, in addition to the 44 targets shared by both IRP1 and IRP2, microarray analysis of IRP-binding transcripts also identified 101 potential IRP1-specific targets and 113 potential IRP2-specific targets. The contribution of these targets in the pathogenesis of $\operatorname{Irp} 1^{-/-}$and $\operatorname{Irp} 2^{-/-}$mice is not clear yet, and characterization of these IRP1- or IRP2- specific targets could shed new light on the unique functions of IRP1 and IRP2 in iron metabolism and development. In addition to the different expression profiles of IRP1 and IRP2 in cells and tissues affected by IRP1 and IRP2 deficiency, we have to keep in mind that the expression profiles of other genes including IRP targets as well as other iron metabolism related genes are also unique in each of these cell types and tissues. Since IRP targets share the same IRE-binding protein pool, changes in mRNA expression of each of these IRP targets will create a unique gene expression context and thereby inevitably affect the binding of IRPs to other targets, which eventually leads to the diseases of Irp1 and Irp2 deficiency animals. Since there have been very few attempts to understand iron metabolism in gene expression context (Hower et al., 2009), application of systemic biology methodologies probably could elucidate a better picture of the molecular pathophysiology of disease in the $\operatorname{Irp1^{-/-}}$ and $\operatorname{Irp} 2^{-/-}$mice.

\section{CLINICAL IMPLICATIONS}

The IRP/IRE system plays an essential role in iron homeostasis, and dysregulation of IRP/IRE system has been reported to cause many diseases. Mutations in the IRE element of human L-ferritin disrupt the regulation of IRPs on L-ferritin translation and result in high ferritin expression and early onset cataracts, causing hereditary hyperferritinemia cataract syndrome (Ismail et al., 2006). A mutation in the IRE of human H-ferritin causes autosomal dominant iron overload (Kato et al., 2001). Disruption of IRE elements in the mouse FPN1 promoter alters erythropoiesis and iron homeostasis, and induces age-dependent loss of photoreceptors of the retina (Mok et al., 2004a,b; Iacovelli et al., 2009). These diseases and phenotypes highlight the essential role of IRP/IRE machinery in iron metabolism and development. The neurodegeneration and anemia of $\operatorname{Irp} 2^{-/-}$mice and the polycythemia and pulmonary hypertension of $\operatorname{Irp} 1^{-/-}$mice underline the essential role of IRP/IRE machinery in regulating cellular and systemic iron homeostasis, and also suggest that mutations of IRP1 and IRP2 could underlie some human diseases. Though patients with diseases attributable to IRP2 mutations have not been identified, such patients could be treated by activating IRP1 with stable nitroxide, Tempol, or other nitric oxide sources, which could compensate for the loss of IRP2 and ameliorate disease, as demonstrated by alleviation of symptoms in Tempoltreated Irp2 $2^{-/-}$mice (Lipinski et al., 2005; Ghosh et al., 2008; Jeong et al., 2011).

Polycythemia is a severe disease that stresses the cardiovascular system and endangers the lives of patients. A routine treatment for polycythemia is phlebotomy to remove excess blood from patient. The essential role of IRP1 in regulating HIF $2 \alpha$ translation, as displayed by $\operatorname{Irp} 1^{-/-}$mice, suggests that activation of IRP1 by 
Tempol or nitric oxide could repress HIF $2 \alpha$ translation and thereby decrease EPO expression and reduce RBC production. Activation of IRP1 could be a therapeutic strategy to treat Chuvash polycythemia patients. Erythropoiesis-stimulating agents have been widely used to treat anemia of chronic diseases, and the significant role of IRP1 in repressing HIF $2 \alpha$ and EPO production suggests that inhibiting the interaction between IRP1 and HIF $2 \alpha$ with small molecules could increase HIF2 $\alpha$ translation and upregulate endogenous EPO levels (Zimmer et al., 2008). Phenotypes of $\operatorname{Irp1} 1^{-/-}$mice also suggest that IRP1 mutations could cause idiopathic polycythemia and pulmonary hypertension in some patients, and IRP1 should be screened as a candidate disease gene in these patients. Irp1 $1^{-/}$mice provide a novel mouse model for pulmonary hypertension, cardiac hypertrophy and aneurysm, and investigations of this model will provide insights into the molecular mechanisms of these diseases. Iron deficiency anemia is one of the most common diseases worldwide. The translational derepression of HIF $2 \alpha$ and subsequent increase of EPO levels in $\operatorname{Irp1} 1^{-/-}$ mice prove that IRP1 plays a critical role in balancing erythropoiesis and systemic iron homeostasis during iron deficiency; these observations explain why the first manifestation of iron deficiency is usually anemia.

\section{FUTURE DIRECTIONS}

The phenotypes of $\operatorname{Ir} p 1^{-/-}$and $\operatorname{Ir} p 2^{-/-}$mice provide compelling evidence for the essential role of the IRP/IRE system in systemic iron homeostasis and physiology, suggesting that IRP1 or IRP2 mutations could cause human diseases similar to those discovered in animal models. Screening human patients and identifying IRP1 or IRP2 mutations could deepen our understanding of their roles in human iron metabolism. $\operatorname{Irp} 1^{-/-}$mice on low iron diet died from peritoneal hemorrhage, and the physiological function of IRP1 in the pulmonary and cardiovascular system is not clear yet. Low iron treatment exacerbates the polycythemia but not pulmonary hypertension, and the molecular mechanism remains to be elucidated. Pharmacological activation of IRP1 could be a therapeutic strategy to treat Chuvash polycythemia and pulmonary hypertension, and inhibition of the interaction between IRP1 and HIF $2 \alpha$ could increase EPO production and potentially treat anemia, and thus modulations of IRP1 activity should be investigated further. As IRP1 is a bifunctional enzyme, $\operatorname{Irp} 1^{-/-}$mice lose both the IRE-binding activity and cytosolic aconitase activity, and the contribution and significance of cytosolic aconitase activity of IRP1 in vivo merits further investigation. Microarray analysis of IRP1- and IRP2- associated mRNAs identified 35 novel mRNAs that can bind both IRP1 and IRP2, as well as mRNAs bind exclusively to either IRP1 or IRP2, and experimental analysis and characterization of those mRNAs could advance our understanding of the function of IRP/IRE system in systemic iron metabolism (Sanchez et al., 2011).

\section{ACKNOWLEDGMENT}

This work was supported by the intramural programs of NICHD.

\section{REFERENCES}

Abboud, S., and Haile, D. J. (2000). A novel mammalian iron-regulated protein involved in intracellular iron metabolism. J. Biol. Chem. 275, 19906-19912. doi: 10.1074/jbc.M000713200
Anderson, S. A., Nizzi, C. P., Chang, Y. I., Deck, K. M., Schmidt, P. J., Galy, B., et al. (2013). The IRP1-HIF-2 $\alpha$ axis coordinates iron and oxygen sensing with erythropoiesis and iron absorption. Cell Metab. 17, 282-290. doi: 10.1016/j.cmet.2013.01.007

Brusselmans, K., Compernolle, V., Tjwa, M., Wiesener, M. S., Maxwell, P. H., Collen, D., et al. (2003). Heterozygous deficiency of hypoxia-inducible factor- $2 \alpha$ protects mice against pulmonary hypertension and right ventricular dysfunction during prolonged hypoxia. J. Clin. Invest. 111, 1519-1527. doi: 10.1172/ JCI15496

Bushuev, V. I., Miasnikova, G. Y., Sergueeva, A. I., Polyakova, L. A., Okhotin, D., Gaskin, P. R., et al. (2006). Endothelin-1, vascular endothelial growth factor and systolic pulmonary artery pressure in patients with Chuvash polycythemia. Haematologica 91, 744-749.

Camaschella, C., Campanella, A., De Falco, L., Boschetto, L., Merlini, R., Silvestri, L., et al. (2007). The human counterpart of zebrafish shiraz shows sideroblastic-like microcytic anemia and iron overload. Blood 110, 1353-1358. doi: 10.1182/blood2007-02-072520

Casarrubea, D., Viatte, L., Hallas, T., Vasanthakumar, A., Eisenstein, R. S., Schumann, K., et al. (2013). Abnormal body iron distribution and erythropoiesis in a novel mouse model with inducible gain of iron regulatory protein (IRP)-1 function. J. Mol. Med. (Berl.) 91, 871-881. doi: 10.1007/s00109-0131008-2

Chollangi, S., Thompson, J. W., Ruiz, J. C., Gardner, K. H., and Bruick, R. K. (2012). Hemerythrin-like domain within F-box and leucine-rich repeat protein 5 (FBXL5) communicates cellular iron and oxygen availability by distinct mechanisms. J. Biol. Chem. 287, 23710-23717. doi: 10.1074/jbc.M112. 360404

Chua, A. C., Olynyk, J. K., Leedman, P. J., and Trinder, D. (2004). Nontransferrinbound iron uptake by hepatocytes is increased in the $\mathrm{Hfe}$ knockout mouse model of hereditary hemochromatosis. Blood 104, 1519-1525. doi: 10.1182/blood-200311-3872

Chung, J., Anderson, S. A., Gwynn, B., Deck, K. M., Chen, M. J., Langer, N. B., et al. (2014). Iron regulatory protein-1 protects against mitoferrin-1deficient porphyria. J. Biol. Chem. 289, 7835-7843. doi: 10.1074/jbc.M114. 547778

Cooperman, S. S., Meyron-Holtz, E. G., Olivierre-Wilson, H., Ghosh, M. C., McConnell, J. P., and Rouault, T. A. (2005). Microcytic anemia, erythropoietic protoporphyria, and neurodegeneration in mice with targeted deletion of iron-regulatory protein 2. Blood 106, 1084-1091. doi: 10.1182/blood-200412-4703

Dandekar, T., Stripecke, R., Gray, N. K., Goossen, B., Constable, A., Johansson, H. E., et al. (1991). Identification of a novel iron-responsive element in murine and human erythroid delta-aminolevulinic acid synthase mRNA. EMBO J. 10, 1903-1909.

Darshan, D., Frazer, D. M., and Anderson, G. J. (2010). Molecular basis of iron-loading disorders. Expert Rev. Mol. Med. 12, e36. doi: $10.1017 /$ S1462399410001687

Donovan, A., Brownlie, A., Zhou, Y., Shepard, J., Pratt, S. J., Moynihan, J., etal. (2000). Positional cloning of zebrafish ferroportin1 identifies a conserved vertebrate iron exporter. Nature 403, 776-781. doi: 10.1038/ 35001596

Duffy, S. P., Shing, J., Saraon, P., Berger, L. C., Eiden, M. V., Wilde, A., et al. (2010). The Fowler Syndrome associated protein FLVCR2 is an importer of heme. Mol. Cell. Biol. 30, 5318-5324. doi: 10.1128/MCB.00690-10

Ferring-Appel, D., Hentze, M. W., and Galy, B. (2009). Cell-autonomous and systemic context-dependent functions of iron regulatory protein 2 in mammalian iron metabolism. Blood 113, 679-687. doi: 10.1182/blood-2008-05155093

Fleming, M. D., Romano, M. A., Su, M. A., Garrick, L. M., Garrick, M. D., and Andrews, N. C. (1998) Nramp2 is mutated in the anemic Belgrade (b) rat: evidence of a role for Nramp2 in endosomal iron transport. Proc. Natl. Acad. Sci. U.S.A. 95, 1148-1153. doi: 10.1073/pnas.95.3.1148

Formenti, F., Beer, P. A., Croft, Q. P., Dorrington, K. L., Gale, D. P., Lappin, T. R., et al. (2011). Cardiopulmonary function in two human disorders of the hypoxiainducible factor (HIF) pathway: von Hippel-Lindau disease and HIF-2 $\alpha$ gain-offunction mutation. FASEB J. 25, 2001-2011. doi: 10.1096/fj.10-177378

Galy, B., Ferring, D., Minana, B., Bell, O., Janser, H. G., Muckenthaler, M., et al. (2005). Altered body iron distribution and microcytosis in mice deficient in iron 
regulatory protein 2 (IRP2). Blood 106, 2580-2589. doi: 10.1182/blood-2005-041365

Galy, B., Ferring-Appel, D., Becker, C., Gretz, N., Grone, H. J., Schumann, K., et al. (2013). Iron regulatory proteins control a mucosal block to intestinal iron absorption. Cell Rep. 3, 844-857. doi: 10.1016/j.celrep.2013. 02.026

Galy, B., Ferring-Appel, D., Kaden, S., Grone, H. J., and Hentze, M. W. (2008). Iron regulatory proteins are essential for intestinal function and control key iron absorption molecules in the duodenum. Cell Metab. 7, 79-85. doi: 10.1016/j.cmet.2007.10.006

Galy, B., Holter, S. M., Klopstock, T., Ferring, D., Becker, L., Kaden, S., et al. (2006). Iron homeostasis in the brain: complete iron regulatory protein 2 deficiency without symptomatic neurodegeneration in the mouse. Nat. Genet. 38, 967-969; discussion 969-970. doi: 10.1038/ng0906-967

Galy, B., Ferring-Appel, D., Sauer, S. W., Kaden, S., Lyoumi, S., Puy, H., etal. (2010). Iron regulatory proteins secure mitochondrial iron sufficiency and function. Cell Metab. 12, 194-201. doi: 10.1016/j.cmet.2010. 06.007

Ganz, T., and Nemeth, E. (2011). Hepcidin and disorders of iron metabolism. Annu. Rev. Med. 62, 347-360. doi: 10.1146/annurev-med-050109142444

Ganz, T., and Nemeth, E. (2012a). Hepcidin and iron homeostasis. Biochim. Biophys. Acta 1823, 1434-1443. doi: 10.1016/j.bbamcr.2012. 01.014

Ganz, T., and Nemeth, E. (2012b). Iron metabolism: interactions with normal and disordered erythropoiesis. Cold Spring Harb. Perspect. Med. 2, a011668. doi: 10.1101/cshperspect.a011668

Garrick, M. D., Dolan, K. G., Horbinski, C., Ghio, A. J., Higgins, D., Porubcin, M., et al. (2003). DMT1: a mammalian transporter for multiple metals. Biometals 16, 41-54. doi: 10.1023/A:1020702213099

Ghosh, M. C., Tong, W. H., Zhang, D., Ollivierre-Wilson, H., Singh, A., Krishna, M. C., et al. (2008). Tempol-mediated activation of latent iron regulatory protein activity prevents symptoms of neurodegenerative disease in IRP2 knockout mice. Proc. Natl. Acad. Sci. U.S.A. 105, 12028-12033. doi: 10.1073/pnas. 0805361105

Ghosh, M. C., Zhang, D. L., Jeong, S. Y., Kovtunovych, G., OllivierreWilson, H., Noguchi, A., et al. (2013). Deletion of iron regulatory protein 1 causes polycythemia and pulmonary hypertension in mice through translational derepression of HIF2 $\alpha$. Cell Metab. 17, 271-281. doi: 10.1016/j.cmet.2012. 12.016

Gordeuk, V. R., and Prchal, J. T. (2006). Vascular complications in Chuvash polycythemia. Semin. Thromb. Hemost. 32, 289-294. doi: 10.1055/s-2006939441

Gunshin, H., Mackenzie, B., Berger, U. V., Gunshin, Y., Romero, M. F. Boron, W. F., etal. (1997). Cloning and characterization of a mammalian proton-coupled metal-ion transporter. Nature 388, 482-488. doi: 10.1038/ 41343

Haase, V. H. (2013). Regulation of erythropoiesis by hypoxia-inducible factors. Blood Rev. 27, 41-53. doi: 10.1016/j.blre.2012.12.003

Henderson, B. R., Seiser, C., and Kuhn, L. C. (1993). Characterization of a second RNA-binding protein in rodents with specificity for iron-responsive elements. J. Biol. Chem. 268, 27327-27334.

Hentze, M. W., Muckenthaler, M. U., and Andrews, N. C. (2004). Balancing acts: molecular control of mammalian iron metabolism. Cell 117, 285-297. doi: 10.1016/S0092-8674(04)00343-5

Hickey, M. M., Lam, J. C., Bezman, N. A., Rathmell, W. K., and Simon, M. C. (2007). von Hippel-Lindau mutation in mice recapitulates Chuvash polycythemia via hypoxia-inducible factor- $2 \alpha$ signaling and splenic erythropoiesis. J. Clin. Invest. 117, 3879-3889.

Hickey, M. M., Richardson, T., Wang, T., Mosqueira, M., Arguiri, E., Yu, H., et al. (2010). The von Hippel-Lindau Chuvash mutation promotes pulmonary hypertension and fibrosis in mice. J. Clin. Invest. 120, 827-839. doi: 10.1172/JCI36362

Hower, V., Mendes, P., Torti, F. M., Laubenbacher, R., Akman, S., Shulaev, V., et al. (2009). A general map of iron metabolism and tissue-specific subnetworks. Mol. Biosyst. 5, 422-443. doi: 10.1039/b816714c

Iacovelli, J., Mlodnicka, A. E., Veldman, P., Ying, G. S., Dunaief, J. L., and Schumacher, A. (2009). Brain and retinal ferroportin 1 dysregulation in polycythaemia mice. Brain Res. 1289, 85-95. doi: 10.1016/j.brainres.2009. 06.098

Ismail, A. R., Lachlan, K. L., Mumford, A. D., Temple, I. K., and Hodgkins, P. R. (2006). Hereditary hyperferritinemia cataract syndrome: ocular, genetic, and biochemical findings. Eur. J. Ophthalmol. 16, 153-160.

Jenkins, P. V., Rawley, O., Smith, O. P., and O’Donnell, J. S. (2012). Elevated factor VIII levels and risk of venous thrombosis. Br. J. Haematol. 157, 653-663. doi: 10.1111/j.1365-2141.2012.09134.x

Jeong, S. Y., Crooks, D. R., Wilson-Ollivierre, H., Ghosh, M. C., Sougrat, R., Lee, J., et al. (2011). Iron insufficiency compromises motor neurons and their mitochondrial function in irp2-null mice. PLoS ONE 6:e25404. doi: 10.1371/journal.pone.0025404

Kato, J., Fujikawa, K., Kanda, M., Fukuda, N., Sasaki, K., Takayama, T., et al. (2001). A mutation, in the iron-responsive element of $\mathrm{H}$ ferritin mRNA, causing autosomal dominant iron overload. Am. J. Hum. Genet. 69, 191-197. doi: 10.1086/ 321261

Keel, S. B., Doty, R. T., Yang, Z., Quigley, J. G., Chen, J., Knoblaugh, S., et al. (2008). A heme export protein is required for red blood cell differentiation and iron homeostasis. Science 319, 825-828. doi: 10.1126/science. 1151133

Kim, H. Y., Klausner, R. D., and Rouault, T. A. (1995). Translational repressor activity is equivalent and is quantitatively predicted by in vitro RNA binding for two iron-responsive element-binding proteins, IRP1 and IRP2. J. Biol. Chem. 270, 4983-4986. doi: 10.1074/jbc.270.10.4983

Kim, H. Y., LaVaute, T., Iwai, K., Klausner, R. D., and Rouault, T. A. (1996). Identification of a conserved and functional iron-responsive element in the $5^{\prime}$-untranslated region of mammalian mitochondrial aconitase. J. Biol. Chem. 271, 24226-24230. doi: 10.1074/jbc.271.39.24226

Kohler, S. A., Henderson, B. R., and Kuhn, L. C. (1995). Succinate dehydrogenase b mRNA of Drosophila melanogaster has a functional iron-responsive element in its $5^{\prime}$-untranslated region. J. Biol. Chem. 270, 30781-30786. doi: 10.1074/jbc.270.51.30781

Laftah, A. H., Latunde-Dada, G. O., Fakih, S., Hider, R. C., Simpson, R. J., and McKie, A. T. (2009). Haem and folate transport by proton-coupled folate transporter/haem carrier protein 1 (SLC46A1). Br. J. Nutr. 101, 1150-1156. doi: $10.1017 /$ S0007114508066762

LaVaute, T., Smith, S., Cooperman, S., Iwai, K., Land, W., Meyron-Holtz, E., et al. (2001). Targeted deletion of the gene encoding iron regulatory protein-2 causes misregulation of iron metabolism and neurodegenerative disease in mice. Nat. Genet. 27, 209-214. doi: 10.1038/84859

Lee, F. S., and Percy, M. J. (2011). The HIF pathway and erythrocytosis. Annu. Rev. Pathol. 6, 165-192. doi: 10.1146/annurev-pathol-011110130321

Lipinski, P., Starzynski, R. R., Drapier, J. C., Bouton, C., Bartlomiejczyk, T., Sochanowicz, B., etal. (2005). Induction of iron regulatory protein 1 RNA-binding activity by nitric oxide is associated with a concomitant increase in the labile iron pool: implications for DNA damage. Biochem. Biophys. Res. Commun. 327, 349-55. doi: 10.1016/j.bbrc.2004. 12.012

Livesey, J. A., Manning, R. A., Meek, J. H., Jackson, J. E., Kulinskaya, E., Laffan, M. A., et al. (2012). Low serum iron levels are associated with elevated plasma levels of coagulation factor VIII and pulmonary emboli/deep venous thromboses in replicate cohorts of patients with hereditary haemorrhagic telangiectasia. Thorax 67, 328-333. doi: 10.1136/thoraxjnl-2011-201076

Majmundar, A. J., Wong, W. J., and Simon, M. C. (2010). Hypoxia-inducible factors and the response to hypoxic stress. Mol. Cell 40, 294-309. doi: 10.1016/j.molcel.2010.09.022

Mastrogiannaki, M., Matak, P., Keith, B., Simon, M. C., Vaulont, S., and Peyssonnaux, C. (2009). HIF-2 $\alpha$, but not HIF- $1 \alpha$, promotes iron absorption in mice. J. Clin. Invest. 119, 1159-1166. doi: 10.1172/ JCI38499

McKie, A. T., Barrow, D., Latunde-Dada, G. O., Rolfs, A., Sager, G., Mudaly, E., etal. (2001). An iron-regulated ferric reductase associated with the absorption of dietary iron. Science 291, 1755-1759. doi: 10.1126/science. 1057206

McKie, A. T., Marciani, P., Rolfs, A., Brennan, K., Wehr, K., Barrow, D., et al. (2000). A novel duodenal iron-regulated transporter, IREG1, implicated in the basolateral 
transfer of iron to the circulation. Mol. Cell 5, 299-309. doi: 10.1016/S10972765(00)80425-6

Medenbach, J., Seiler, M., and Hentze, M. W. (2011). Translational control via protein-regulated upstream open reading frames. Cell 145, 902-913. doi: 10.1016/j.cell.2011.05.005

Melefors, O. (1996). Translational regulation in vivo of the Drosophila melanogaster mRNA encoding succinate dehydrogenase iron protein via iron responsive elements. Biochem. Biophys. Res. Commun. 221, 437-441. doi: 10.1006/bbrc.1996.0613

Meyron-Holtz, E. G., Ghosh, M. C., Iwai, K., LaVaute, T., Brazzolotto, X., Berger, U. V., et al. (2004). Genetic ablations of iron regulatory proteins 1 and 2 reveal why iron regulatory protein 2 dominates iron homeostasis. EMBO J. 23, 386-395. doi: 10.1038/sj.emboj.7600041

Mok, H., Jelinek, J., Pai, S., Cattanach, B. M., Prchal, J. T., Youssoufian, H., et al. (2004a). Disruption of ferroportin 1 regulation causes dynamic alterations in iron homeostasis and erythropoiesis in polycythaemia mice. Development 131, 1859-1868. doi: 10.1242/dev.01081

Mok, H., Mendoza, M., Prchal, J. T., Balogh, P., and Schumacher, A. (2004b). Dysregulation of ferroportin 1 interferes with spleen organogenesis in polycythaemia mice. Development 131, 4871-4881. doi: 10.1242/ dev. 01342

Moroishi, T., Nishiyama, M., Takeda, Y., Iwai, K., and Nakayama, K. I. (2011). The FBXL5-IRP2 axis is integral to control of iron metabolism in vivo. Cell Metab. 14, 339-351. doi: 10.1016/j.cmet.2011.07.011

Muckenthaler, M. U., Galy, B., and Hentze, M. W. (2008). Systemic iron homeostasis and the iron-responsive element/iron-regulatory protein (IRE/IRP) regulatory network. Annu. Rev. Nutr. 28, 197-213. doi: 10.1146/annurev.nutr.28.061807.155521

Nemeth, E., Tuttle, M. S., Powelson, J., Vaughn, M. B., Donovan, A., Ward, D. M., et al. (2004). Hepcidin regulates cellular iron efflux by binding to ferroportin and inducing its internalization. Science 306, 2090-2093. doi: $10.1126 /$ science. 1104742

Ohgami, R. S., Campagna, D. R., Greer, E. L., Antiochos, B., McDonald, A., Chen, J., et al. (2005). Identification of a ferrireductase required for efficient transferrin-dependent iron uptake in erythroid cells. Nat. Genet. 37, 1264-1269. doi: $10.1038 / \mathrm{ng} 1658$

Pantopoulos, K. (2004). Iron metabolism and the IRE/IRP regulatory system: an update. Ann. N. Y. Acad. Sci. 1012, 1-13. doi: 10.1196/annals 1306.001

Pawlus, M. R., and Hu, C. J. (2013). Enhanceosomes as integrators of hypoxia inducible factor (HIF) and other transcription factors in the hypoxic transcriptional response. Cell. Signal. 25, 1895-1903. doi: 10.1016/j.cellsig.2013. 05.018

Potten, C. S. (1998). Stem cells in gastrointestinal epithelium: numbers, characteristics and death. Philos. Trans. R. Soc. Lond. B Biol. Sci. 353, 821-830. doi 10.1098/rstb.1998.0246

Qiu, A., Jansen, M., Sakaris, A., Min, S. H., Chattopadhyay, S., Tsai, E., et al. (2006). Identification of an intestinal folate transporter and the molecular basis for hereditary folate malabsorption. Cell 127, 917-928. doi: 10.1016/j.cell.2006. 09.041

Quigley, J. G., Yang, Z., Worthington, M. T., Phillips, J. D., Sabo, K. M., Sabath, D. E., et al. (2004). Identification of a human heme exporter that is essential for erythropoiesis. Cell 118, 757-766. doi: 10.1016/j.cell.2004.08.014

Rajagopal, A., Rao, A. U., Amigo, J., Tian, M., Upadhyay, S. K., Hall, C., et al. (2008). Haem homeostasis is regulated by the conserved and concerted functions of HRG-1 proteins. Nature 453, 1127-1131. doi: 10.1038/nature06934

Recalcati, S., Alberghini, A., Campanella, A., Gianelli, U., De Camilli, E., Conte, D., et al. (2006). Iron regulatory proteins 1 and 2 in human monocytes, macrophages and duodenum: expression and regulation in hereditary hemochromatosis and iron deficiency. Haematologica 91, 303-310.

Rigby, P.G. (1971). The utilization of iron. Clin. Toxicol. 4, 559-569. doi: $10.3109 / 15563657108990978$

Rouault, T. A. (2006). The role of iron regulatory proteins in mammalian iron homeostasis and disease. Nat. Chem. Biol. 2, 406-414. doi: 10.1038/nchembio807 Rouault, T. A. (2009). Cell biology. An ancient gauge for iron. Science 326, 676-677. doi: $10.1126 /$ science. 1181938

Rouault, T. A. (2013). Iron metabolism in the CNS: implications for neurodegenerative diseases. Nat. Rev. Neurosci. 14, 551-564. doi: 10.1038/nrn3453
Salahudeen, A. A., Thompson, J. W., Ruiz, J. C., Ma, H. W., Kinch, L. N., Li, Q., etal. (2009). An E3 ligase possessing an iron-responsive hemerythrin domain is a regulator of iron homeostasis. Science 326, 722-726. doi: $10.1126 /$ science. 1176326

Sanchez, M., Galy, B., Muckenthaler, M. U., and Hentze, M. W. (2007). Iron-regulatory proteins limit hypoxia-inducible factor- $2 \alpha$ expression in iron deficiency. Nat. Struct. Mol. Biol. 14, 420-426. doi: 10.1038/ nsmb 1222

Sanchez, M., Galy, B., Schwanhaeusser, B., Blake, J., Bahr-Ivacevic, T., Benes, V., et al. (2011). Iron regulatory protein-1 and -2: transcriptome-wide definition of binding mRNAs and shaping of the cellular proteome by iron regulatory proteins. Blood 118, e168-e179. doi: 10.1182/blood-2011-04-343541

Sarkar, B. (1970). State of iron(III) in normal human serum: low molecular weight and protein ligands besides transferrin. Can. J. Biochem. 48, 1339-1350. doi: 10.1139/o70-208

Schalinske, K. L., Chen, O. S., and Eisenstein, R. S. (1998). Iron differentially stimulates translation of mitochondrial aconitase and ferritin mRNAs in mammalian cells. Implications for iron regulatory proteins as regulators of mitochondrial citrate utilization. J. Biol. Chem. 273, 3740-3746. doi: 10.1074/jbc.273. 6.3740

Semenza, G. L. (2009). Involvement of oxygen-sensing pathways in physiologic and pathologic erythropoiesis. Blood 114, 2015-2019. doi: 10.1182/blood-2009-05189985

Shah, Y. M., and Xie, L. (2013). Hypoxia-inducible factors link iron homeostasis and erythropoiesis. Gastroenterology 146, 630-642. doi: 10.1053/j.gastro.2013. 12.031

Shah, Y. M., Matsubara, T., Ito, S., Yim, S. H., and Gonzalez, F. J. (2009). Intestinal hypoxia-inducible transcription factors are essential for iron absorption following iron deficiency. Cell Metab. 9, 152-164. doi: 10.1016/j.cmet.2008. 12.012

Shao, D., Park, J. E., and Wort, S. J. (2011). The role of endothelin-1 in the pathogenesis of pulmonary arterial hypertension. Pharmacol. Res. 63, 504-511. doi: 10.1016/j.phrs.2011.03.003

Shaw, G. C., Cope, J. J., Li, L., Corson, K., Hersey, C., Ackermann, G. E., et al. (2006). Mitoferrin is essential for erythroid iron assimilation. Nature 440, 96-100. doi: 10.1038 /nature 04512

Smith, S. R., Ghosh, M. C., Ollivierre-Wilson, H., Hang Tong, W., and Rouault, T. A. (2006). Complete loss of iron regulatory proteins 1 and 2 prevents viability of murine zygotes beyond the blastocyst stage of embryonic development. Blood Cells Mol. Dis. 36, 283-287. doi: 10.1016/j.bcmd.2005. 12.006

Theil, E. C. (1990). Regulation of ferritin and transferrin receptor mRNAs. J. Biol. Chem. 265, 4771-4774.

Theil, E. C. (2012). Ferritin protein nanocages-the story. Nanotechnol. Percept. 8, 7-16. doi: 10.4024/N03TH12A.ntp.08.01

Thorin, E., and Clozel, M. (2010). The cardiovascular physiology and pharmacology of endothelin-1. Adv. Pharmacol. 60, 1-26. doi: 10.1016/B978-0-12-3850614.00001-5

Tong, W. H., and Rouault, T. A. (2007). Metabolic regulation of citrate and iron by aconitases: role of iron-sulfur cluster biogenesis. Biometals 20, 549-564. doi: 10.1007/s10534-006-9047-6

Vashisht, A. A., Zumbrennen, K. B., Huang, X., Powers, D. N., Durazo, A., Sun, D., etal. (2009). Control of iron homeostasis by an ironregulated ubiquitin ligase. Science 326, 718-721. doi: 10.1126/science. 1176333

Wallander, M. L., Leibold, E. A., and Eisenstein, R. S. (2006). Molecular control of vertebrate iron homeostasis by iron regulatory proteins. Biochim. Biophys. Acta 1763, 668-689. doi: 10.1016/j.bbamcr.2006.05.004

West, A. R., and Oates, P. S. (2008). Mechanisms of heme iron absorption: current questions and controversies. World J. Gastroenterol. 14, 4101-4110. doi: 10.3748/wjg. 14.4101

White, C., Yuan, X., Schmidt, P. J., Bresciani, E., Samuel, T. K., Campagna, D., etal. (2013). HRG1 is essential for heme transport from the phagolysosome of macrophages during erythrophagocytosis. Cell Metab. 17, 261-270. doi: 10.1016/j.cmet.2013.01.005

Wilcox, C. S., and Pearlman, A. (2008). Chemistry and antihypertensive effects of tempol and other nitroxides. Pharmacol. Rev. 60, 418-469. doi: $10.1124 /$ pr. 108.000240 
Wilkinson, N., and Pantopoulos, K. (2013). IRP1 regulates erythropoiesis and systemic iron homeostasis by controlling HIF $2 \alpha$ mRNA translation. Blood 122 , 1658-1668. doi: 10.1182/blood-2013-03-492454

Wingert, R. A., Galloway, J. L., Barut, B., Foott, H., Fraenkel, P., Axe, J. L., etal. (2005). Deficiency of glutaredoxin 5 reveals Fe-S clusters are required for vertebrate haem synthesis. Nature 436, 1035-1039. doi: 10.1038/ nature 03887

Ye, H., and Rouault, T. A. (2010). Erythropoiesis and iron sulfur cluster biogenesis. Adv. Hematol. 2010, 329394. doi: 10.1155/2010/ 329394

Ye, H., Jeong, S. Y., Ghosh, M. C., Kovtunovych, G., Silvestri, L., Ortillo, D., etal. (2010). Glutaredoxin 5 deficiency causes sideroblastic anemia by specifically impairing heme biosynthesis and depleting cytosolic iron in human erythroblasts. J. Clin. Invest. 120, 1749-1761. doi: 10.1172/ JCI40372

Yoon, D., Ponka, P., and Prchal, J. T. (2011). Hypoxia. 5. Hypoxia and hematopoiesis Am. J. Physiol. Cell Physiol. 300 C1215-C1222. doi: 10.1152/ajpcell. 00044.2011

Zimmer, M., Ebert, B. L., Neil, C., Brenner, K., Papaioannou, I., Melas, A., et al. (2008). Small-molecule inhibitors of HIF-2a translation link its 5'UTR iron-responsive element to oxygen sensing. Mol. Cell 32, 838-848. doi: 10.1016/j.molcel.2008.12.004
Zumbrennen, K., Holter, S., Becker, L., Rathkolb, B., Rodansky, E., and Leibold, E. (2009). A novel Irp2-/- mouse model displays locomotor dysfunction and neuronal iron accumulation. International BioIron Society Meeting. Am. J. Hematol. 84, E257.

Conflict of Interest Statement: The authors declare that the research was conducted in the absence of any commercial or financial relationships that could be construed as a potential conflict of interest.

Received: 04 April 2014; paper pending published: 16 April 2014; accepted: 10 May 2014; published online: 13 June 2014.

Citation: Zhang D-L, Ghosh MC and Rouault TA (2014) The physiological functions of iron regulatory proteins in iron homeostasis - an update. Front. Pharmacol. 5:124. doi: 10.3389/fphar.2014.00124

This article was submitted to Drug Metabolism and Transport, a section of the journal Frontiers in Pharmacology.

Copyright (c) 2014 Zhang, Ghosh and Rouault. This is an open-access article distributed under the terms of the Creative Commons Attribution License (CC BY). The use, distribution or reproduction in other forums is permitted, provided the original author $(s)$ or licensor are credited and that the original publication in this journal is cited, in accordance with accepted academic practice. No use, distribution or reproduction is permitted which does not comply with these terms. 